\title{
Pharmacokinetics and Milk Penetration of Orbifloxacin After Intravenous, Subcutaneous, and Intramuscular Administration to Lactating Goats
}

\author{
P. Marín, ${ }^{1}$ E. Escudero, E. Fernández-Varón, and C. M. Cárceles \\ Department of Pharmacology, Faculty of Veterinary Medicine, University of Murcia, Campus de Espinardo, 30071 Murcia, Spain
}

\begin{abstract}
The single-dose disposition kinetics of orbifloxacin were determined in clinically normal lactating goats $(\mathrm{n}=6)$ after intravenous, subcutaneous, and intramuscular administration of $2.5 \mathrm{mg}$ of orbifloxacin $/ \mathrm{kg}$ of body weight. Orbifloxacin concentrations were determined by HPLC with fluorescence detection. The concentration-time data were analyzed by compartmental and noncompartmental kinetic methods. Steady-state volume of distribution and clearance of orbifloxacin after intravenous administration were $1.13 \pm 0.08 \mathrm{~L} / \mathrm{kg}$ and $0.40 \pm 0.11 \mathrm{~L} / \mathrm{h} \cdot \mathrm{kg}$, respectively. Following subcutaneous and intramuscular administration, orbifloxacin achieved maximum plasma concentrations of $1.85 \pm$ 0.20 and $1.66 \pm 0.14 \mathrm{mg} / \mathrm{L}$ at $1.25 \pm 0.22$ and $0.87 \pm$ $0.38 \mathrm{~h}$, respectively. The absolute bioavailabilities after subcutaneous and intramuscular routes were $108.96 \pm$ $17.61 \%$ and $105.01 \pm 15.61 \%$, respectively. Orbifloxacin penetration from the blood into the milk was rapid and showed high levels of concentrations in milk secretion. From this data, orbifloxacin could have success against susceptible mastitis pathogens in goats.
\end{abstract}

Key words: orbifloxacin, pharmacokinetics, lactating goat, milk

\section{INTRODUCTION}

Fluoroquinolones are antimicrobial drugs that generally have very good activities against a broad spectrum of aerobic bacteria, including Pasteurella spp., and against mycoplasma (Giles et al., 1991; Gutiérrez and Rodríguez, 1993; Hannan et al., 1997). The main target site for their bactericidal action is the DNA-gyrase, an enzyme required for supercoiling of DNA to provide spatial arrangement of DNA in the bacterial cell. Fluoroquinolones have other good characteristics such as large volumes of distribution, low plasma protein bind-

Received February 2, 2007.

Accepted May 16, 2007.

${ }^{1}$ Corresponding author: pmarin@um.es ing, and relatively low MIC against susceptible target microorganisms (Brown, 1996). Orbifloxacin is a new synthetic fluoroquinolone antimicrobial drug that has been developed especially for use in veterinary medicine, and it could be useful in lactating goats. In Japan, intramuscular administration of this drug has been shown to be effective and safe for the treatment of gastrointestinal and respiratory infections in cattle and swine (Nakamura, 1995).

In Europe, the problem of mastitis is highly relevant not only for the economic losses to producers, but also for the hygienic and safety production of dairy products intended for human consumption, particularly with respect to bacteriological quality. Intramammary infections in dairy goats are mainly of bacterial origin. Most of the published papers about mastitis treatments report clinical observations or recommendations adapted from results obtained in cows. Inappropriate low doses of an antibiotic can lead to ineffective therapeutic blood or milk concentrations and increased risk of development of resistant microorganisms. Equally, toxicity may result if the extrapolated dose is too high.

For systemic mastitis therapy to be useful, effective passage of the drug from blood to the foci of infection must be achieved. The extent to which a drug has access into milk when given systemically depends on its main pharmacokinetic properties: lipid solubility, degree of ionization, and extent of binding to serum and udder proteins (Ziv, 1980). Drug disposition may change as an outcome of disease states. The milk to serum concentration ratio for drugs is often unknown in goats. The pharmacokinetic properties of orbifloxacin have been evaluated in horses (Haines et al., 2001; Davis et al., 2006) and dogs (Heinen, 2002), but not yet in lactating goats.

To assess the efficacy of orbifloxacin in mammary gland infections, we calculated the relevant pharmacokinetic parameters that influence its antibacterial activity in the milk and plasma of goats.

\section{MATERIALS AND METHODS}

\section{Animals}

Six clinically healthy Murciano-Granadina female goats weighing between 45.8 and $62.3 \mathrm{~kg}$ and aged from 
5 to $6 \mathrm{yr}$ were obtained from the caprine farm of the University of Murcia (Spain). The animals were housed and fed an antibiotic-free diet for at least $30 \mathrm{~d}$ preceding the study and were observed daily for general health in each treatment period of the crossover. Clinical observations were made before injection and at 2,10 , and $24 \mathrm{~h}$ postinjection. Alfalfa hay and water was provided ad libitum together with a drug-free concentrate.

The study was approved by the Bioethical Committee of the University of Murcia (Spain).

\section{Experimental Design}

A crossover design $(2 \times 2 \times 2)$ was used in 3 phases. Each animal received single intravenous (i.v.), subcutaneous (s.c.), and intramuscular (i.m.) injections of orbifloxacin 5\% (Victas, Dainippon Sumitomo Pharma, Osaka, Japan) at a dose of $2.5 \mathrm{mg} / \mathrm{kg}$ with at least a 15-d washout period.

For the i.v. administration, the solution was injected into the left jugular vein and blood samples $(4 \mathrm{~mL})$ were collected from the contralateral jugular vein into heparinized tubes. Subcutaneous injections were administered under the skin of the back at a single location in the thoraco-lumbar region lateral of the midline, and i.m. injections were administered into the semimembranous muscle. Blood samples were collected at 0 (pretreatment), $0.083,0.167,0.25,0.5,0.75,1,1.5,2$, $4,6,8,10,12,24,36,48$, and $72 \mathrm{~h}$ postdosing. Samples were centrifuged at $1,500 \times g$ for $15 \mathrm{~min}$ and the plasma taken and stored at $-45^{\circ} \mathrm{C}$ until assayed.

Milk samples were collected before and at 1, 2, 4, 6, $8,10,12,24,36,48$, and $72 \mathrm{~h}$ postadministration after complete evacuation of the udder, to avoid a dilution effect during the normal milking routine.

\section{Analytical Method}

Plasma and milk concentrations of orbifloxacin were measured using a modified HPLC method as previously reported (Siefert et al., 1999). The HPLC system was equipped with a model LC-10ASvp pump, an RF-10AXL Fluorescence Detector, and a model SIL-10ADvp autoinjector (Shimadzu, Kyoto, Japan). The above-mentioned system was connected to a computer with a Shimadzu Class-VP Chromatography Data System program (Shimadzu, Washington, DC).

Orbifloxacin pure substance (Schering Plough Corporation, Kenilworth, NJ) was used for quality control. Ciprofloxacin (Vita Pharma, Madrid, Spain) was used as an internal standard. After addition of $10 \mu \mathrm{L}$ of the internal standard to $200 \mu \mathrm{L}$ of plasma or milk, $200 \mu \mathrm{L}$ of acetonitrile was added. Plasma and milk proteins were precipitated by shaking in an ultrasonic bath fol- lowed by centrifugation for $10 \mathrm{~min}$ at $1,600 \times g$. The supernatant was diluted 4-fold with $0.067 M$ disodium hydrogen phosphate buffer ( $\mathrm{pH}$ 7.5) and transferred to HPLC autosampler vials. The HPLC separation was performed using a reverse-phase Discovery $\mathrm{C}_{18}$ column $(250 \times 4 \mathrm{~mm} ; 5-\mu \mathrm{m}$ particle size; Supelco, Bellefonte, PA) with an injection volume of $60 \mu \mathrm{L}$. Autosampler vials and column temperature was set at $5^{\circ} \mathrm{C}$. The mobile phase consisted of acetonitrile (14\%) and tetrabutylammonium hydrogen sulfate solution ( $5 \mathrm{~g} / \mathrm{L} ; 86 \%)$ using an isocratic method with a flow rate of $1.0 \mathrm{~mL} /$ min. Orbifloxacin eluted at approximately $10.3 \mathrm{~min}$. Fluorescence detection was performed at an excitation wavelength of $338 \mathrm{~nm}$ and an emission wavelength of $425 \mathrm{~nm}$.

\section{Method Validation}

This method was validated before the start of sample analysis. The selectivity of the method was demonstrated because no interfering peaks from endogenous compounds in the blank goat plasma or milk samples were observed with the same retention time as orbifloxacin and ciprofloxacin in the chromatograms of blank samples.

Control samples were prepared from a pool of blank goat plasma or milk spiked with 9 concentrations of orbifloxacin between 25 and $2,000 \mu \mathrm{g} / \mathrm{L}$. Plasma and milk aliquots were stored at $-45^{\circ} \mathrm{C}$ until assay. Aliquots of controls were extracted as above and $60 \mu \mathrm{L}$ of each was injected into the chromatographic system. Standard curves were obtained by unweighed linear regression of orbifloxacin peak areas vs. known concentrations. Each point was established from an average of 5 determinations. Correlation coefficients $(r)$ were $>0.99$ for calibration curves. Percentage recovery was determined by comparison of the peak areas of plasma and milk blank samples spiked with different amounts of drug and treated as any samples, with the peak areas of the same standards prepared in phosphate buffer. Each point was established from an average of 5 determinations. The mean percentage recoveries of orbifloxacin from plasma and milk were $94.78 \pm 3.25$ and 92.02 $\pm 5.26 \%$, respectively. The assay precision (relative standard deviation, RSD) was assessed by expressing the standard deviation of repeated measurements as a percentage of the mean value. Intraday precision was estimated from 6 replicates of 3 standard samples (plasma or milk) used for calibration curves (RSD $<5.6 \%$ ). Interday precision was estimated from the analysis of standard samples (plasma or milk) on 3 separate days (RSD $<7.4 \%$ ). The limit of detection was determined as 3 times the signal:noise ratio at the time of elution of the analyte and was $20 \mu \mathrm{g} / \mathrm{L}$ for plasma and 
milk. The limit of quantification was $25 \mu \mathrm{g} / \mathrm{L}$ for plasma and milk.

\section{Pharmacokinetic Analysis}

The plasma concentration-time data obtained after each treatment in each individual animal were initially fitted to 1-, 2-, and 3-exponential equations by the retroprojection method (Gibaldi and Perrier, 1982). The PKCALC computer program (Shumaker, 1986) was used to obtain the best estimates of the parameters of these equations. The final curve fitting was carried out using nonlinear regression with the MULTI computer program and the Gauss-Newton damping algorithm (Yamaoka et al., 1981). Akaike's information criterion (Yamaoka et al., 1978) was used to determine the best equation that defined plasma concentration-time data for each animal and the most appropriate weighing of these data. Pharmacokinetic parameters were obtained from the individual fitted equations (Gibaldi and Perrier, 1982). The absorption and disposition half-lives were calculated as $\mathrm{t}^{1} / 2 \mathrm{ka}=\ln 2 / \mathrm{k}_{\mathrm{a}}, \mathrm{t}^{1 / 2} \lambda 1=\ln 2 / \lambda_{1}$, and $\mathrm{t} 1 / 2 \lambda \mathrm{z}=\ln 2 / \lambda_{\mathrm{z}}$, respectively.

A noncompartmental model was used to determine the area under the concentration-time curve (AUC), using the linear trapezoidal rule with extrapolation to infinity time. Mean residence time (MRT) was calculated as AUMC/AUC, where AUMC is total area under the first moment curve. Mean absorption times (MAT) were calculated as $\mathrm{MRT}_{\text {s.c., i.m. }}-\mathrm{MRT}_{\text {i.v. }}$. Systemic clearance $(\mathrm{Cl})$ was estimated as Dose/AUC. The apparent volumes of distribution at steady state $\left(\mathbf{V}_{\text {ss }}\right)$ were calculated as (dose-AUMC)/AUC ${ }^{2}$.

Biovailability (F) was calculated by the method of corresponding areas:

$$
\mathrm{F}(\%)=\mathrm{AUC}_{\mathrm{SC}, \mathrm{IM}} \times 100 / \mathrm{AUC}_{I V} .
$$

The milk concentration-time data were analyzed by noncompartmental methods using WinNonlin Professional program (version 5.1; Pharsight Corporation, Mountain View, CA). Drug concentration at each sampling time interval and the volume of milk at each time interval were used to calculate the cumulative amounts of orbifloxacin eliminated in milk, recovery $(\%)$, and terminal half-life; $\mathrm{AUC}_{\text {milk }}$ was calculated using the linear trapezoidal rule with extrapolation to infinity.

\section{Statistical Analysis}

Descriptive statistical parameters as mean, standard deviation, and coefficient of variation were calculated. Harmonic means were calculated for the half-lives of disposition and absorption. The Wilcoxon Rank Sum

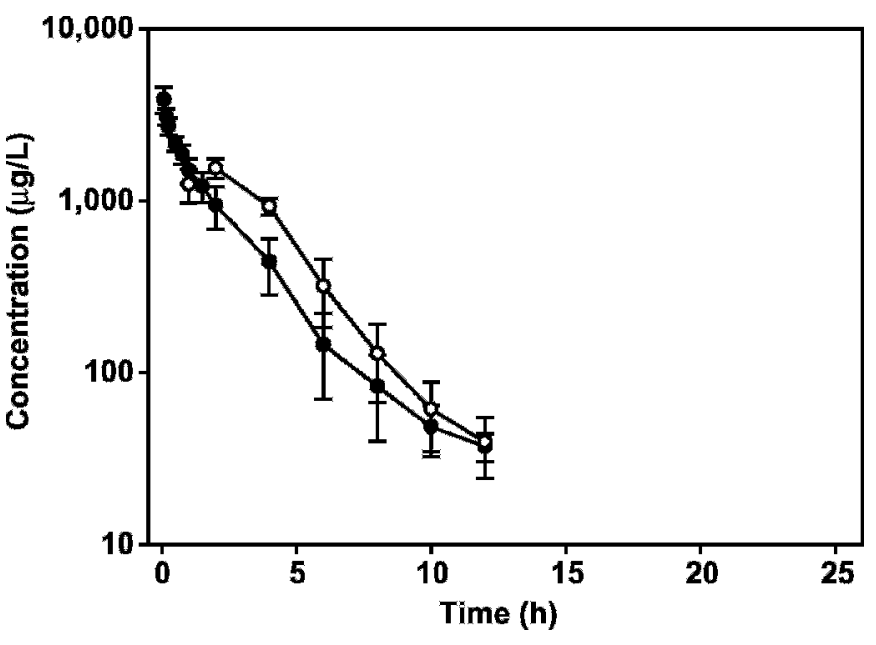

Figure 1. Semilogarithmic plot of the plasma (- - - ) and milk (-O-) concentrations (mean $\pm \mathrm{SD}$ ) of orbifloxacin following a single intravenous dose of $2.5 \mathrm{mg} / \mathrm{kg}$ of BW $(\mathrm{n}=6)$.

test and the Student's $t$-test were used to test parameters for significant differences between i.v., s.c., and i.m. administration (Powers, 1990); SPSS (version 11.0; SPSS Inc., Chicago, IL) statistical software was used.

\section{RESULTS}

The orbifloxacin plasma concentration vs. time data after i.v., s.c., and i.m. administration could best be described by a 2-compartment open model, for which the general polyexponential equation is

$$
C=\sum_{i=1}^{n} C_{i} \cdot e^{-\lambda i \cdot t}
$$

where $\mathbf{C}$ is plasma concentration of drug, t is time after drug administration, $\mathrm{C}_{\mathrm{i}}$ and $\lambda_{\mathrm{i}}$ are the intercept and slope, respectively, of the different disposition phases, and $\mathrm{e}$ is the base of natural logarithm. The mean $( \pm \mathrm{SD})$ plasma and milk concentrations of orbifloxacin following i.v., s.c., and i.m. administration are plotted in Figures 1, 2, and 3, respectively. After s.c. administration, only one goat showed detectable milk concentration at $24 \mathrm{~h}$ postdose. The mean ( $\pm \mathrm{SD}$ ) pharmacokinetic parameters based on compartmental and noncompartmental pharmacokinetic analyses are presented in Table 1.

Clinical examination of all the goats before and after each trial revealed no abnormalities. No local or systemic adverse reactions occurred after i.v., s.c., and i.m. injection of orbifloxacin.

Milk production per day was $1.52 \pm 0.57 \mathrm{~L}$ (mean $\pm \mathrm{SD})$. 


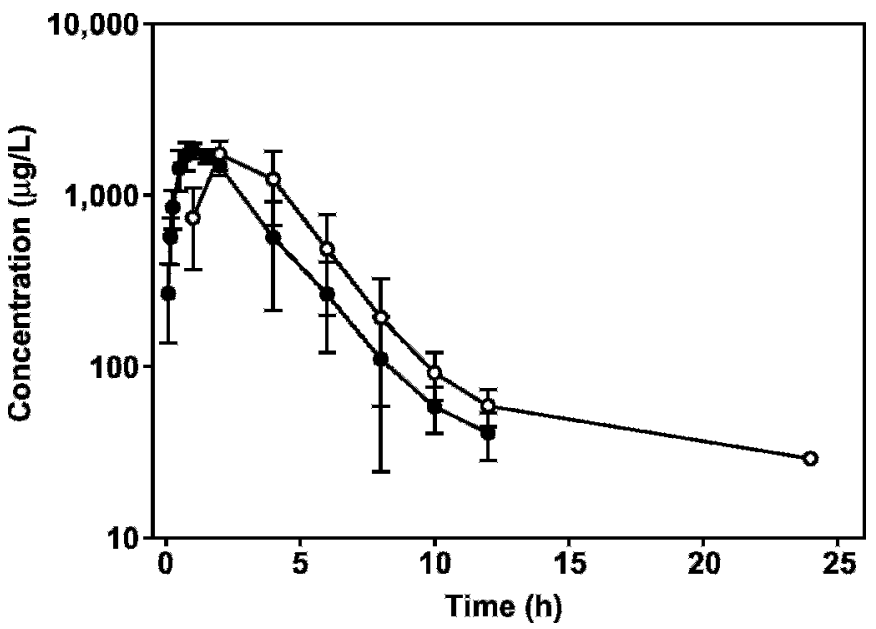

Figure 2. Semilogarithmic plot of the plasma (- - ) and milk (- $\mathrm{O}-$ ) concentrations (mean $\pm \mathrm{SD}$ ) of orbifloxacin following a single subcutaneous dose of $2.5 \mathrm{mg} / \mathrm{kg}$ of BW $(\mathrm{n}=6)$.

\section{DISCUSSION}

The pharmacokinetics of orbifloxacin in lactating goats is reported in the present study for the first time. The disposition of orbifloxacin according to a 2-compartment open model is in agreement with other pharmacokinetics studies with fluoroquinolones in goats (Abd ElAty and Goudah, 2002; Marín et al., 2007a,b).

Apparent volume of distribution at steady state $\left(\mathrm{V}_{\mathrm{ss}}=\right.$ $1.13 \pm 0.08 \mathrm{~L} / \mathrm{kg}$ ) suggests good penetration through biological membranes. This $\mathrm{V}_{\mathrm{ss}}$ value is in agreement with those found in horses $\left(\mathrm{V}_{\mathrm{ss}}=1.58 \mathrm{~L} / \mathrm{kg}\right.$; Davis et al., 2006), and for other fluoroquinolones in lactating

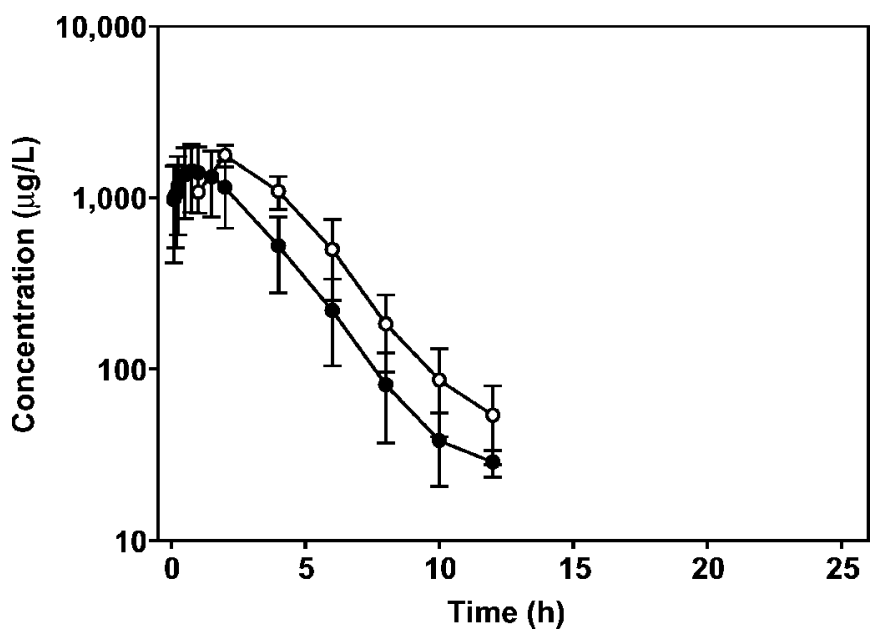

Figure 3. Semilogarithmic plot of the plasma (- - ) and milk (-O-) concentrations (mean $\pm \mathrm{SD}$ ) of orbifloxacin following a single intramuscular dose of $2.5 \mathrm{mg} / \mathrm{kg}$ of BW $(\mathrm{n}=6)$. goats (Fernández-Varón et al., 2006b; Marín et al., 2007b).

The terminal half-life $\left(t^{1} / 2 \lambda z\right)$ after i.v. dosing was 4.12 $\mathrm{h}$, very close to that reported for difloxacin in goats (4.92; Marín et al., 2007b) and orbifloxacin in horses (5.08; Davis et al., 2006), and longer than those registered for other fluoroquinolones in lactating goats (Fernández-Varón et al., 2006b; Marín et al., 2007a). The terminal half-life values following s.c. and i.m. administration were 4.99 and $3.34 \mathrm{~h}$, respectively. This last value was shorter than that observed following i.v. injection. Therefore, the absorption process does not seem to affect elimination of orbifloxacin. The fact that the terminal half-life value after i.v. dosing was longer than that after i.m. dosing is not usual in pharmacokinetics studies; it has, however, been reported for other fluoroquinolones in goats (Aliabadi and Lees, 2001), sheep (Aliabadi et al., 2003), and horses (Fernández-Varón et al., 2006a). Orbifloxacin was well absorbed following s.c. and i.m. administration with absolute bioavailability of 108.96 and $105.01 \%$, respectively. Similar values have been reported for other fluoroquinolones in goats, such as marbofloxacin (100.74\%; Waxman et al., 2001), moxifloxacin (96.87\%; Fernández-Varón et al., 2006b), difloxacin (90.16 and 106.79\%; Marín et al., 2007b), and danofloxacin (110\%; Aliabadi and Lees, 2001). However, bioavailability after s.c. and i.m. administration in the goats of the present study was greater than that reported for orbifloxacin after oral dosing in horses (68.35\%; Davis et al., 2006).

The various solute transport and secretion processes involved in milk production offer pathways for the movement of drug molecules from plasma to milk (McManaman and Neville, 2003). For the movement of drugs from plasma to milk, however, passive diffusion seems to be the most likely route of transport.

Most drugs are either weak organic acids or bases and exist in solution (in plasma or milk) in both ionized and un-ionized forms. The proportion of the drug that is in the un-ionized state is dependent on the $\mathrm{pKa}$ (dissociation constant) value of the drug and the $\mathrm{pH}$ of the environment, with the $\mathrm{pKa}$ of the drug being the $\mathrm{pH}$ at which $50 \%$ of the drug molecules are in the ionized state. If the drug molecule itself is sufficiently lipophilic, the un-ionized form is able to diffuse across the lipid membranes. Another important factor that affects distribution of drugs into tissues is the extent of reversible binding to proteins in the solvent (plasma or milk) and tissues. This is a nonspecific interaction between drug and proteins that results in the formation of drug-protein complexes, which are too large to cross tissue membranes (Gehring and Smith, 2006).

Orbifloxacin, like other fluoroquinolones, is amphoteric because of the presence of a carboxylic acid and 
Table 1. Pharmacokinetic parameters (mean \pm SD) of orbifloxacin in goats after intravenous, subcutaneous, and intramuscular administration at a dose of $2.5 \mathrm{mg} / \mathrm{kg}$ of BW $(\mathrm{n}=6)$

\begin{tabular}{|c|c|c|c|c|}
\hline Parameter & Unit & Intravenous & Subcutaneous & Intramuscular \\
\hline \multicolumn{5}{|l|}{ Plasma } \\
\hline $\mathrm{K}_{\mathrm{a}}$ & $\mathrm{h}^{-1}$ & - & $1.16 \pm 0.32$ & $1.02 \pm 0.27$ \\
\hline$\lambda_{1}$ & $\mathrm{~h}^{-1}$ & $0.66 \pm 0.17$ & $0.65 \pm 0.14$ & $0.77 \pm 0.25$ \\
\hline$\lambda_{\mathrm{z}}$ & $\mathrm{h}^{-1}$ & $0.17 \pm 0.03$ & $0.17 \pm 0.02^{\mathrm{b}}$ & $0.24 \pm 0.02^{\mathrm{a}}$ \\
\hline $\mathrm{t}^{1 / 2 \mathrm{ka}}$ & $\mathrm{h}$ & - & $0.63 \pm 0.02$ & $0.65 \pm 0.14$ \\
\hline$t^{1 / 2 \lambda} 1$ & $\mathrm{~h}$ & $1.12 \pm 0.15$ & $1.10 \pm 0.07$ & $0.92 \pm 0.02$ \\
\hline $\mathrm{t}^{1 / 2 \lambda \mathrm{z}}$ & $\mathrm{h}$ & $4.12 \pm 0.32$ & $4.99 \pm 0.09^{b}$ & $3.34 \pm 0.05$ \\
\hline $\mathrm{V}_{\mathrm{ss}}$ & $\mathrm{L} / \mathrm{kg}$ & $1.13 \pm 0.08$ & - & - \\
\hline AUC & $\mathrm{mg} \cdot \mathrm{h} / \mathrm{L}$ & $6.15 \pm 1.42$ & $6.47 \pm 1.24$ & $5.98 \pm 0.62$ \\
\hline MRT & $\mathrm{h}$ & $2.75 \pm 0.41$ & $3.58 \pm 0.54^{\mathrm{a}}$ & $2.82 \pm 0.37^{\mathrm{a}}$ \\
\hline $\mathrm{Cl}$ & $\mathrm{L} / \mathrm{h} \cdot \mathrm{kg}$ & $0.40 \pm 0.11$ & - & - \\
\hline MAT & $\mathrm{h}$ & - & $0.89 \pm 0.15$ & $0.10 \pm 0.07$ \\
\hline $\mathrm{C}_{\max }$ & $\mathrm{mg} / \mathrm{L}$ & - & $1.85 \pm 0.20$ & $1.66 \pm 0.14$ \\
\hline $\mathrm{T}_{\max }$ & $\mathrm{h}$ & - & $1.25 \pm 0.22$ & $0.87 \pm 0.38$ \\
\hline $\mathrm{F}$ & $\%$ & - & $108.96 \pm 17.61$ & $105.01 \pm 15.61$ \\
\hline \multicolumn{5}{|l|}{ Milk } \\
\hline $\mathrm{C}_{\max }$ & $\mathrm{mg} / \mathrm{L}$ & $1.56 \pm 0.18$ & $1.73 \pm 0.30$ & $1.77 \pm 0.23^{\mathrm{a}}$ \\
\hline $\mathrm{T}_{\max }$ & $\mathrm{h}$ & $1.83 \pm 0.37$ & $2.00 \pm 0.00$ & $2.00 \pm 0.00$ \\
\hline Recovery & $\%$ & $0.28 \pm 0.07$ & $0.32 \pm 0.10$ & $0.34 \pm 0.06$ \\
\hline$t^{1 / 2 \lambda z}$ & $\mathrm{~h}$ & $1.84 \pm 0.16$ & $1.93 \pm 0.32$ & $1.94 \pm 0.36$ \\
\hline $\mathrm{AUC}_{\text {milk }}$ & $\mathrm{mg} \cdot \mathrm{h} / \mathrm{L}$ & $6.36 \pm 0.70$ & $7.58 \pm 2.61$ & $7.43 \pm 1.27$ \\
\hline $\mathrm{C}_{\text {max-milk }} / \mathrm{C}_{\text {max-plasma }}$ & - & - & $0.95 \pm 0.20$ & $1.05 \pm 0.21$ \\
\hline $\mathrm{AUC}_{\text {milk }} / \mathrm{AUC}_{\text {plasma }}$ & - & $1.02 \pm 0.14$ & $1.15 \pm 0.17$ & $1.21 \pm 0.19^{\mathrm{a}}$ \\
\hline
\end{tabular}

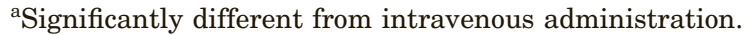

${ }^{\mathrm{b}}$ Significantly different from intramuscular administration.

${ }^{1}$ Plasma parameters: $\mathrm{t}^{1} / 2 \lambda 1=$ disposition half-life associated with the initial slope $\left(\lambda_{1}\right)$ of a semilogarithmic concentration-time curve (harmonic mean); $\mathrm{t}^{1} / 2 \lambda \mathrm{z}=$ disposition half-life associated with the terminal slope $\left(\lambda_{\mathrm{z}}\right)$ of a semilogarithmic concentration-time curve (harmonic mean); $\mathrm{V}_{\mathrm{ss}}=$ apparent volume of distribution at steady state; $\mathrm{AUC}=$ area under the plasma concentration-time curve from zero to infinity; $\mathrm{MRT}=$ mean residence time; $\mathrm{Cl}=$ total body clearance of drug from the plasma; $\mathrm{F}=$ fraction of the administered dose systemically available (bioavailability); $\mathrm{T}_{\max }=$ time to reach peak or maximum plasma concentration following subcutaneous and intramuscular administration; $\mathrm{k}_{\mathrm{a}}=$ absorption rate constant (first order); $\mathrm{t}^{1} / 2 \mathrm{ka}=$ absorption half-life (harmonic mean); MAT = mean absorption time; and $\mathrm{C}_{\max }=$ peak or maximum plasma concentration following subcutaneous and intramuscular administration.

${ }^{2}$ Milk parameters: $\mathrm{T}_{\max }=$ time to reach peak or maximum milk concentration following subcutaneous and intramuscular administration; $\mathrm{C}_{\max }=$ peak or maximum milk concentration following subcutaneous and intramuscular administration; $\mathrm{t}^{1 / 2 \lambda \mathrm{z}}=$ disposition half-life associated with the terminal slope $\left(\lambda_{\mathrm{z}}\right)$ of a semilogarithmic concentration-time curve (harmonic mean); and $\mathrm{AUC}_{\text {milk }}=$ area under the milk concentration-time curve from zero to infinity.

one or more basic amine functional groups. At a $\mathrm{pH}$ between 6 and 8 , this compound is sufficiently lipidsoluble to be able to penetrate tissues (Brown, 1996). Therefore, the extensive penetration of orbifloxacin from blood to goat's milk was predictable based on the ion trap mechanism (Atkinson and Begg, 1990). We used 2 ratios to evaluate the penetration of orbifloxacin into milk: $\mathrm{AUC}_{\text {milk }} / \mathrm{AUC}_{\text {plasma }}$ and $\mathrm{C}_{\text {max-milk }} / \mathrm{C}_{\text {max-plasma }}$. The $\mathrm{AUC}_{\text {milk }} / \mathrm{AUC}_{\text {plasma }}$ ratios were $1.02,1.15$, and 1.21 after i.v., s.c., and i.m. administration, respectively. These data show extensive penetration of orbifloxacin into the milk. Moreover, the $\mathrm{C}_{\text {max-milk }} / \mathrm{C}_{\text {max-plasma }}$ ratio $(\geq 1)$ showed that high concentrations of orbifloxacin were reached in milk after s.c. and i.m. dosing. These findings are in agreement with several reports of other fluoroquinolones in lactating animals (Shem-Tov et al., 1997; Abd El-Aty and Goudah, 2002; Fernández-Varón et al., 2006b).
Fluoroquinolones exhibit concentration-dependent killing, and it is therefore not necessary to maintain their concentrations above the MIC throughout the entire dosing period. These drugs are likely to be highly effective when given in large doses at infrequent intervals (Boothe, 1994; Nightingale et al., 2000). Because of this, peak milk concentration is a very important parameter. In this study, the milk $\mathrm{C}_{\max }$ following i.v., s.c., and i.m. dosing $\left(\mathrm{C}_{\max }=1.56,1.73\right.$, and $1.77 \mathrm{mg} /$ $\mathrm{L}$, respectively) was greater than those reported for pefloxacin in lactating goats (dose: $10 \mathrm{mg} / \mathrm{kg}$; Abd ElAty and Goudah, 2002) and for danofloxacin in ewes (dose: $1.25 \mathrm{mg} / \mathrm{kg}$; Shem-Tov et al., 1997).

For concentration-dependent antibacterial agents, overall efficacy is related to AUC, and the AUC/MIC index is the most important factor that determines efficacy (Vogelman et al., 1988). Other authors have shown that $\mathrm{C}_{\max }$ is important not only for determining antibac- 
terial effect in the postantibiotic phase, but also for killing the more resistant subpopulations of bacteria. Therefore, $\mathrm{C}_{\max } / \mathrm{MIC}$ is important for determining overall efficacy, and it has a pronounced effect on the emergence of antibiotic resistance (Aliabadi and Lees, 2001). Consequently, the ratios $\mathrm{C}_{\max } / \mathrm{MIC}_{90}$ and $\mathrm{AUC}_{24} / \mathrm{MIC}_{90}$ are the best parameters for predicting the antimicrobial effect of fluoroquinolones (Lode et al., 1998). Previous investigations have shown that, for fluoroquinolones, a $\mathrm{C}_{\max } / \mathrm{MIC}_{90}$ ratio $>3$ produced $99 \%$ reduction in bacterial count, and a $\mathrm{C}_{\max } / \mathrm{MIC}_{90}$ ratio of $\geq 8$ prevented the emergence of resistant microorganisms (Craig, 1998). Furthermore, an $\mathrm{AUC}_{24} / \mathrm{MIC}_{90}>100 \mathrm{~h}$ should be achieved to give maximum clinical and bacteriological efficacy (Turnidge, 1999).

The MIC data of orbifloxacin against caprine bacterial isolates have not been reported until now. Taking into account the MIC of other veterinary fluoroquinolones against sensitive strains of microorganisms of veterinary importance (Hannan et al., 1997; Watts et al., 1997), and using the surrogate marker $\mathrm{C}_{\max } / \mathrm{MIC}=8$, orbifloxacin could be effective by the s.c. and i.m. routes at $2.5 \mathrm{mg} / \mathrm{kg}$ against mastitis isolates with MIC $\leq 0.22$ $\mu \mathrm{g} / \mathrm{mL}$. Using the $\mathrm{AUC}_{24} / \mathrm{MIC}_{90}=100 \mathrm{~h}$ index, orbifloxacin would have success against microorganisms that are able to produce mastitis in goats with MIC $\leq 0.08$ $\mu \mathrm{g} / \mathrm{mL}$ after i.m. dosing and MIC $\leq 0.07 \mu \mathrm{g} / \mathrm{mL}$ after s.c. administration. However, it should be noted that the numerical values of these ratios used to predict optimal dosage have been generated in experimental infections in laboratory animals (neutropenic mice) or in human clinical trials (Toutain and Lees, 2004), and that these numerical values may or may not be applicable to goat infections, or to animal infections in general.

We also have to take into account that inflammation of the mammary gland leads to vascular permeability changes and differences in milk composition. Milk pH generally increases, milk casein concentrations decrease, milk albumin concentrations increase, somatic cells increase, and milk fat contents can decrease when inflammation is present. All of these factors could modify the pharmacokinetics of drugs; their exact importance is not, however, well understood (Gehring and Smith, 2006). For example, the study of Fang and Pyörälä (1996) showed that normal milk reduced the activity of enrofloxacin against Escherichia coli strains by only a factor of 2 , but maintained similar activity in mastitic milk.

These data allow us to conclude that orbifloxacin administered subcutaneously and intramuscularly to lactating goats at a dose rate of $2.5 \mathrm{mg} / \mathrm{kg}$ was characterized by extensive absorption, high systemic availability, and high distribution into the udder. Consequently, orbifloxacin could be useful in the treatment of severe systemic infections and those affecting the udder in goats after specific assessment of susceptible microorganisms.

\section{ACKNOWLEDGMENTS}

Thanks are due to Schering Plough (Kenilworth, NJ) for supplying orbifloxacin pure substance, to Dainippon Sumitomo Pharma (Osaka, Japan) for supplying commercial product (Victas), and to J. Carrizosa for his assistance with the experiments.

\section{REFERENCES}

Abd El-Aty, A. M., and A. Goudah. 2002. Some pharmacokinetic parameters of pefloxacin in lactating goats. Vet. Res. Commun. 26:553-561.

Aliabadi, F., M. F. Landoni, and P. Lees. 2003. Pharmacokinetics (PK), Pharmacodynamics (PD), and PK-PD integration of danofloxacin in sheep biological fluids. Antimicrob. Agents Chemother. 47:626-635.

Aliabadi, F., and P. Lees. 2001. Pharmacokinetics and pharmacodynamics of danofloxacin in serum and tissue fluids of goats following intravenous and intramuscular administration. Am. J. Vet. Res. 62:1979-1989.

Atkinson, H., and E. Begg. 1990. Prediction of drug distribution into human milk from physicochemical characteristics. Clin. Pharmacokinet. 18:151-167.

Boothe, D. M. 1994. Enrofloxacin revisited. Vet. Med. (Praha) 89:744-753.

Brown, S. A. 1996. Fluoroquinolones in animal health. J. Vet. Pharmacol. Ther. 19:1-14.

Craig, W. A. 1998. Pharmacokinetic/pharmacodynamic parameters: Rationale for antibacterial dosing of mice and men. Clin. Infect. Dis. 26:1-10.

Davis, J. L., M. G. Papich, and A. Weingarten. 2006. The pharmacokinetics of orbifloxacin in the horse following oral and intravenous administration. J. Vet. Pharmacol. Ther. 29:191-197.

Fang, W., and S. Pyörälä. 1996. Mastitis-causing Escherichia coli: Serum sensitivity and susceptibility to selected antibacterials in milk. J. Dairy Sci. 79:76-82.

Fernández-Varón, E., I. Ayala, P. Marín, A. Carrión, N. Martos, E. Escudero, and C. M. Cárceles. 2006a. Pharmacokinetics of danofloxacin in horses after intravenous, intramuscular and intragastric administration. Equine Vet. J. 38:342-346.

Fernández-Varón, E., L. Villamayor, E. Escudero, A. Espuny, and C. M. Cárceles. 2006b. Pharmacokinetics and milk penetration of moxifloxacin after intravenous and subcutaneous administration to lactating goats. Vet. J. 172:302-307.

Gehring, R., and G. W. Smith. 2006. An overview of factors affecting the disposition of intramammary preparations used to treat bovine mastitis. J. Vet. Pharmacol. Ther. 29:237-241.

Gibaldi, M., and P. Perrier. 1982. Pharmacokinetics. Marcel Dekker Inc., New York, NY.

Giles, C. J., R. A. Magonigle, W. T. R. Grimshaw, A. C. Tanner, J. E. Risk, M. J. Lynch, and J. R. Rice. 1991. Clinical pharmacokinetics of parenterally administered danofloxacin in cattle. J. Vet. Pharmacol. Ther. 14:400-410.

Gutiérrez, C. B., and E. F. Rodríguez. 1993. In vitro susceptibility of Pasteurella multocida subspecies multocida strains isolated from swine to 42 antimicrobial agents. Zentralbl. Bakteriol. 270:387-393.

Haines, G. R., M. P. Brown, R. R. Gronwall, K. A. Merritt, and L. K. Baltzley. 2001. Pharmacokinetics of orbifloxacin and its concentration in body fluids and in endometrial tissues of mares. Can. J. Vet. Res. 65:181-187.

Hannan, P. C. T., G. D. Windsor, A. Jong, N. Schmeer, and M. Stegemann. 1997. Comparative susceptibilities of various animal- 
pathogenic mycoplasmas to fluoroquinolones. Antimicrob. Agents Chemother. 41:2037-2040.

Heinen, E. 2002. Comparative serum pharmacokinetics of the fluoroquinolones enrofloxacin, difloxacin, marbofloxacin and orbifloxacin in dogs after single oral administration. J. Vet. Pharmacol. Ther. 25:1-5.

Lode, H., K. Borner, and P. Koeppe. 1998. Pharmacodynamics of fluoroquinolones. Clin. Infect. Dis. 27:33-39.

Marín, P., C. M. Cárceles, E. Escudero, and E. Fernández-Varón. 2007a. Pharmacokinetics and milk penetration of ibafloxacin after intravenous administration to lactating goats. Can. J. Vet. Res. 71:74-76.

Marín, P., E. Escudero, E. Fernández-Varón, and C. M. Cárceles. 2007b. Pharmacokinetics and milk penetration of difloxacin after intravenous, subcutaneous and intramuscular administration to lactating goats. J. Vet. Pharmacol. Ther. 30:74-79.

McManaman, J. L., and M. C. Neville. 2003. Mammary physiology and milk secretion. Adv. Drug Deliv. Rev. 55:629-641.

Nakamura, S. 1995. Veterinary use of the new quinolones in Japan. Drugs 49(Suppl. 2):152-158.

Nightingale, C. H., E. M. Grant, and R. Quintiliani. 2000. Pharmacodynamics and pharmacokinetics of levofloxacin. Chemotherapy 46:6-14.

Powers, J. 1990. Statistical analysis of pharmacokinetics data. J. Vet. Pharmacol. Ther. 13:113-120.

Shem-Tov, M., G. Ziv, A. Glickman, and A. Saran. 1997. Pharmacokinetics and penetration of danofloxacin from the blood into the milk of ewes. Vet. Res. 28:571-579.

Shumaker, R. C. 1986. PKCALC: A basic interactive computer program for statistical and pharmacokinetic analysis of data. Drug Metab. Rev. 17:331-348.
Siefert, H. M., C. Kohlsdorfer, W. Steinke, and A. Witt. 1999. Pharmacokinetics of the 8-methoxyquinolone, moxifloxacin: Tissue distribution in male rats. J. Antimicrob. Chemother. 43(Suppl. B):61-67.

Toutain, P. L., and P. Lees. 2004. Integration and modelling of pharmacokinetic and pharmacodynamic data to optimise dosage regimens in veterinary medicine. J. Vet. Pharmacol. Ther. 27:467477.

Turnidge, J. 1999. Pharmacokinetics and pharmacodynamics of fluoroquinolones. Drugs 58:29-36.

Vogelman, B., S. Gudmundsson, J. Leggett, J. Turnidge, S. Ebert, and W. A. Craig. 1988. Correlation of antibacterial pharmacokinetic parameters with therapeutic efficacy in animal models. J. Infect. Dis. 158:831-847.

Watts, J. L., S. A. Salmon, M. S. Sanchez, and R. J. Yancey. 1997. In vitro activity of premafloxacin, a new extended-spectrum fluoroquinolone, against pathogens of veterinary importance. Antimicrob. Agents Chemother. 41:1190-1192.

Waxman, S., C. Rodríguez, F. González, M. L. De Vicente, M. I. San Andrés, and M. D. San Andrés. 2001. Pharmacokinetic behavior of marbofloxacin after intravenous and intramuscular administrations in adult goats. J. Vet. Pharmacol. Ther. 24:375-378.

Yamaoka, K., T. Nakagawa, and T. Uno. 1978. Application of Akaike's information criterion (AIC) in the evaluation of linear pharmacokinetic equations. J. Pharmacokinet. Biopharm. 6:165-175.

Yamaoka, K., Y. Tamigawara, and J. Uno. 1981. A pharmacokinetic analysis program (MULTI) for microcomputers. J. Pharmacobiodyn. 4:879-885.

Ziv, G. 1980. Drug selection and use in mastitis: Systemic vs. local therapy. J. Am. Vet. Med. Assoc. 176:1109-1115. 